Original Research Article

\title{
The correlation of cardiovascular risk factors and angiographic findings with serum vitamin D levels in patients undergoing coronary angiography
}

\author{
Tripathy S. K. ${ }^{1 *}$, Dhal N. ${ }^{1}$, Pattnaik S. ${ }^{2}$, Routray S. N. ${ }^{3}$, Das S. ${ }^{1}$, Mishra S. K. ${ }^{1}$, Panigrahi M. ${ }^{4}$, \\ Mohanty B. ${ }^{1}$, Behera M. R. ${ }^{1}$
}

${ }^{1}$ Department of Medicine, SCB

Medical College, Cuttack,

Odisha, India

${ }^{2}$ Department of Medicine, Student in Neurology, Bangur Institute of Neurosciences, Kolkata, West Bengal, India ${ }^{3}$ Department of Cardiology, SCB Medical College, Cuttack, Odisha, India

${ }^{4}$ Department of Ophthalmology, District Headquarter Hospital, Kendrapada, Odisha, India

Received: 01 December 2017 Accepted: 07 December 2017

*Correspondence to:

Dr. Tripathy S. K.,

Email: sarojtripathy1@

hotmail.com

Copyright: (C) the author(s), publisher and licensee Medip Academy. This is an openaccess article distributed under the terms of the Creative Commons Attribution NonCommercial License, which permits unrestricted noncommercial use, distribution, and reproduction in any medium, provided the original work is properly cited.

\begin{abstract}
Background: Studies regarding correlation of various conventional risks factors for Coronary Artery Disease (CAD) are many. Keeping in mind the scarcity of studies regarding Vit-D Deficiency (VDD), a new risk factor in CAD, present study was conducted to correlate Vit-D level with conventional risk factors and Coronary Angiography (CAG).

Methods: Hundred adult patients admitted to Medicine and Cardiology undergoing CAG with suspected or established CAD were kept in study. Patients having renal, hepatic, parathyroid disease, osteomalacia and patients taking drugs interfering with Vitamin D (Vit-D) metabolism were excluded. After detailed history and thorough clinical examination, routine investigations and 25-(OH) D level was estimated. Subsequently patients underwent CAG. Statistical analysis by Mann Whitey test and Chi-square Test was done and inference was drawn.

Results: 100 patients in different age groups had hypertension (HTN) in 53, diabetics mellitus (DM) 39, dyslipidemia 62, smokers 38 and family history of CAD 19. CAG showed normal coronaries in 4, Single Vessel Disease (SVD) in 30, double vessel diseases (DVD) 43 and triple vessel disease (TVD) 22. Vit-D level <20ng/ml i.e. Vit-D deficiency (VDD) in $68,20-30 \mathrm{ng} / \mathrm{ml}$ i.e. Vit-D insufficiency (VDI) in 22 and $>30 \mathrm{ng} / \mathrm{ml}$ (normal) in 10. VDD was profound in 51-60 and 61-70 years age groups. Statistical correlation of VDD was not significant with conventional risk factors, but statistically significant correlation of VDD was observed with dyslipidemia and CAG findings in our study.

Conclusions: Like earlier studies we observed significant correlation of Vit-D levels with CAD. Though dyslipidemia was significantly correlated with VDD, correlation of other conventional risk factors like age, sex, HTN, DM, smoking and family history was not found. We conclude from this study presence of significant association of VDD with severe CAD. DVD and TVD by CAG were common with low Vit-D levels.
\end{abstract}

Keywords: Coronary artery disease, Coronary angiogram, Vit-D insufficiency, 25- $(\mathrm{OH}) \mathrm{D}$

\section{INTRODUCTION}

VDD is now a pandemic cutting across age groups, ruralurban divide and developing or developed countries. ${ }^{1}$
Vitamin D is the common name for a group of sterols and fat-soluble steroids affecting multiple metabolisms in human body. The two important members in vitamin D group for humans are vitamin $\mathrm{D}_{2}$ (Ergocalciferol) which is manufactured by invertebrates and plants after exposure to 
ultra violate radiation (UVR) in sunlight and vitamin $\mathrm{D}_{3}$ (Cholecalciferol) which is naturally present in small range of foods and also manufactured endogenously form 7dehydrocholesterol in the skin by UVR fall after sun exposure. Apart from sun exposure and dietary intake Vitamin $\mathrm{D}_{3}$ can be acquired from pharmaceutical preparations. Exogenously acquired vitamin $\mathrm{D}_{3}$ is biologically inactive and it comprises only $10-20 \%$ of total Vitamin $\mathrm{D}_{3}$ in the body and requires two hydroxylation processes first in liver to $25-(\mathrm{OH}) \mathrm{D}$ and second in kidneys converting it to $1,25-(\mathrm{OH}) \mathrm{D}$. As $25-(\mathrm{OH}) \mathrm{D}$ has long halflife and is the major circulating hormone least affected by serum calcium, serum parathormone and phosphate, estimation of this $25-(\mathrm{OH}) \mathrm{D}$ is clinically important.

VDD has high prevalence worldwide (Estimated one billion) and is alarming as VDD has been associated with various diseases like DM, HTN, CAD, metabolic syndrome (MS), cognitive decline, osteoarthritis (OA), auto immune diseases like type $1 \mathrm{DM}$ and various malignancies (especially that of digestive tract). ${ }^{1}$ High prevalence of VDD in India is attributed to changing food habits, phosphate and phytates in high fiber diet depleting vitamin D stores, cultural habits of burqa and purdah (hampering UVR fall on skin), increasing pollution, unplanned and unspaced pregnancies (VDD in both mother and baby) and high incidence of renal, hepatic, inflammatory diseases, tuberculosis, sepsis and dermatological disorders Chapuy MC in their French study of 20 cities showed higher prevalence of VDD in northern cities due to lack of direct sun exposure. ${ }^{2}$ Ginde AA comparing 1994-1998 National Health and Nutrition Examination Study III (NHANES-III) with 2001-2004 data demonstrated marked decrease in vitamin D level. ${ }^{3}$ Hari Narayan CV, Indian study demonstrated vitamin D level to be low in urban adults than their rural counterparts. ${ }^{4}$ Goswami, also observed vitamin D level to be higher in people exposed to direct sunlight. ${ }^{5}$ Mithal A, related various factors with VDD in global population and demonstrated that factor responsible for VDD are advanced age, institution or home bound status, sunscreen use, heavily pigmented skin, northern latitude, air pollution, prolonged exclusive breast feeding, smoking, obesity, malabsorption syndrome, renal or liver diseases, anti-epileptic and anti-HIV medications. ${ }^{6}$ Forman JP, analysing health Professionals follow-up study and nurse's health study showed risk of incident HTN to be inversely related with $25-(\mathrm{OH}) \mathrm{D} \mathrm{level}^{7}$

The mechanism of HTN in VDD is postulated to be due to RAAS inhibition and hyperparathyroidism. ${ }^{8,9}$ Goel RK, observed decrease in blood pressure with Vitamin D supplementation. ${ }^{10}$ Pittas AG, observed relatively constant inverse relationship of VDD with prevalence of Type2DM. ${ }^{11}$ Isaia G, showed high prevalence of VDD in female type-2DM. ${ }^{12}$ Chiu KC, Californian study demonstrated direct relationship of vitamin $\mathrm{D}$ level with insulin sensitivity and VDD having negative effect on $\beta$-cell function. $^{13}$ Kelishadi R, did meta-analysis of 17 cross sectional studies and observed high vitamin $\mathrm{D}$ level to be associated with more favourable lipid profile in pediatric age group. ${ }^{14}$ Ford ES demonstrated inverse relationship of vitamin D level with MS. ${ }^{15}$ Smoking causes decrease in Nitric Oxide (NO) availability and inhibits translocation of vitamin $\mathrm{D}$ receptor from the nucleus to the cell membrane resulting in VDD. ${ }^{16}$ Cardio vascular diseases (CVD) specially CAD has shown a steep rise in last few decades in India due to rising trend of obesity, high blood pressure, dyslipidemia, change in food habits, sedentary life style. New emerging risk factors like VDD homocysteine level and inflammation are under recent investigations.

Siadat ZD observed severe VDD in CAD. ${ }^{17}$ Giovannucci $\mathrm{E}$, demonstrated high risk of myocardial infarction with decreasing 25-(OH) D levels in a graded manner even after control of other risk factors. ${ }^{18}$ Bair TL, observed severe VDD in chronic stable CAD and also proposed VDD as the best predictor for future cardiovascular events. ${ }^{19}$ Young KA, observed frequent and severe coronary artery calcification (CAC) representing plaque burden in type$1 \mathrm{DM}$ patients having CAD ${ }^{20}$ Syal SK, observed VDD to be associated with DVD and TVD by angiography. ${ }^{21}$

Aim of the present study was keeping in mind, that paucity of data regarding association vitamin $\mathrm{D}$ level with $\mathrm{CAD}$ in this part of india present study was conducted. The aim was to establish correlation of VDD with the conventional risk factors like DM, HTN, dyslipidemia, smoking and family history of CAD in patients undergoing CAG. Also, CAG findings with vitamin $\mathrm{D}$ level were studied for correlation.

\section{METHODS}

100 consecutive adult (>18yrs) patients of either sex undergoing CAG with suspected or established CAD were included in the study. Patients with renal failure, liver disease, known parathyroid disorder, those taking drugs which interferer with vitamin D metabolism, osteomalacia and pregnancy were excluded. After detailed history and thorough clinical examination investigation like complete hemogram, FBG, lipid profile, urea, creatinine, LFT, urine for albumin by dipstick and vitamin $\mathrm{D}[25-(\mathrm{OH}) \mathrm{D}]$ estimation was done in the Department of Biochemistry by using auto-analyser. [25- $(\mathrm{OH})$ D] was measured using ELISA kit with interpretation of vitamin D level $>30 \mathrm{ng} / \mathrm{ml}$ (Adequate), 20-30ng/ml (insufficient) and $<20 \mathrm{ng} / \mathrm{ml}$ (deficient).

Subsequently ECG and CAG were done in these patients in the Department of Cardiology and interpretation of CAG by the number of vessel affected, severity of the stenosis and severity of CAC was done.

For quantitative variables under different groups undergoing CAG statistically analysis was done by using Mann-whitney test. For qualitative variables chi square test was used. The data were analysed using SPSS statistical software and inference was drawn. 


\section{RESULTS}

In our study 100 patients $[M(n=83)$ and $F(n=17)]$ were found to be in different age groups of <40, 41-50, 51-60, $61-70$ and $>70 y$ rs as $5,14,35,38$ and $8 \%$ respectively. HTN was present in 53, DM in 39 , dyslipidemia in 62 , smoking in 38 , family history of CAD in 19 . CAG interpretation revealed normal coronaries in 4, SVD in 31 , DVD in 43 and TVD in 22 patients.

Vitamin D estimation revealed VDD in 68, VDI in 22 and normal vitamin D level in 10 with maximum of VDD in 51-60 and 61-70yrs age group with 28 and 24 number of patients respectively. No statistically significant correlation was observed with sex $(\mathrm{P}=0.3785)$ and age $(\mathrm{P}=0.289)$ as presented in Table 1 and Table 2.

Table 1: Comparison of vitamin D status according to sex.

\begin{tabular}{|lllll|}
\hline Sex & Vit $<\mathbf{2 0}$ & Vit $\mathbf{2 0 - 3 0}$ & Vit $>\mathbf{3 0}$ & Total \\
\hline Female & 14 & 2 & 1 & 17 \\
\hline Male & 54 & 20 & 9 & 83 \\
\hline Total & 68 & 22 & 10 & 100 \\
\hline
\end{tabular}

Table 2: Correlation of Vitamin D with age group.

\begin{tabular}{|lllll|}
\hline Age group & Vit $<\mathbf{2 0}$ & Vit $\mathbf{2 0 - 3 0}$ & Vit $>\mathbf{3 0}$ & Total \\
\hline 40 or less & 2 & 2 & 1 & 5 \\
\hline $41-50$ & 8 & 4 & 2 & 14 \\
\hline $51-60$ & 28 & 5 & 2 & 35 \\
\hline $61-70$ & 24 & 11 & 3 & 38 \\
\hline More than 70 & 6 & 0 & 2 & 8 \\
\hline Total & 68 & 22 & 10 & 100 \\
\hline
\end{tabular}

In 53 patients with HTN vitamin D level estimation revealed VDD in 37, VDI in 11 and normal in 5, whereas in normotensives this was 31,11 and 5 respectively and the difference was not statistically significant $(\mathrm{P}=0.9185)$ as presented in Table 3 .

Table 3: Correlation between vitamin D and hypertension.

\begin{tabular}{|lllll|}
\hline Hypertension & Vit $<\mathbf{2 0}$ & Vit $\mathbf{2 0 - 3 0}$ & Vit $>\mathbf{3 0}$ & Total \\
\hline $\mathrm{N}$ & 31 & 11 & 5 & 47 \\
\hline $\mathrm{Y}$ & 37 & 11 & 5 & 53 \\
\hline Total & 68 & 22 & 10 & 100 \\
\hline
\end{tabular}

39 out of 100 patients were diabetic in our study and had VDD in 24, VDI in 8 and normal Vitamin D in 7 and in and in comparison, 61 nondiabetics had 44 VDD, 14 VDI and 3 normal and in this no statistically significant difference was observed $(\mathrm{P}=0.105)$ as presented in Table 4 .

Study of dyslipidemia with vitamin D level revealed that in 62 patients having dyslipidemia VDD was found in 48, VDI in 10 and normal vitamin D in 4, whereas in normal lipid profile group there were 20 patients with VDD, 12 with VDI and 6 with normal vitamin D and comparison showed statistically significant correlation of vitamin D level with dyslipidemia $(\mathrm{P}=0.344)$ as presented in Table 5 .

Table 4: Correlation between vitamin D and diabetes mellites.

\begin{tabular}{|lllll|}
\hline Diabetes & Vit $<\mathbf{2 0}$ & Vit $\mathbf{2 0}-\mathbf{3 0}$ & Vit $>\mathbf{3 0}$ & Total \\
\hline $\mathrm{N}$ & 44 & 14 & 3 & 61 \\
\hline $\mathrm{Y}$ & 24 & 8 & 7 & 39 \\
\hline Total & 68 & 22 & 10 & 100 \\
\hline
\end{tabular}

Table 5: Correlation of vitamin D and dyslipidemia.

\begin{tabular}{|lllll|}
\hline Dyslipidemia & Vit $<\mathbf{2 0}$ & Vit $\mathbf{2 0 - 3 0}$ & Vit $>\mathbf{3 0}$ & Total \\
\hline $\mathrm{N}$ & 20 & 12 & 6 & 38 \\
\hline $\mathrm{Y}$ & 48 & 10 & 4 & 62 \\
\hline Total & 68 & 22 & 10 & 100 \\
\hline
\end{tabular}

Vitamin D level in 38 smokers in our study showed VDD in 22, VDI in 11 and normal in 5 whereas in non-smokers this was 46,11 and 5 respectively and comparing it no statistically significant difference was seen $(\mathrm{P}=0.2374)$ as presented in Table 6.

Table 6: Correlation of vitamin D and smoking habit.

\begin{tabular}{|lllll|}
\hline Smoking & Vit $<\mathbf{2 0}$ & Vit $\mathbf{2 0 - 3 0}$ & Vit $>\mathbf{3 0}$ & Total \\
\hline $\mathrm{N}$ & 46 & 11 & 5 & 62 \\
\hline $\mathrm{Y}$ & 22 & 11 & 5 & 38 \\
\hline Total & 68 & 22 & 10 & 100 \\
\hline
\end{tabular}

Regarding presence of family history in CAD and vitamin D level we found 19 patients had family history in our study in which VDD was present in 10, VDI in 5 and normal in 4 and when compared with 81 patients of no family history group VDD, VDI, and normal was found to be 58, 17 and 6 respectively. No statistically significant difference was observed $(\mathrm{P}=0.1438)$ as presented (Table 7).

Table 7: Correlation of vitamin D and family history of cad.

\begin{tabular}{|lllll|}
\hline $\begin{array}{l}\text { Family } \\
\text { history of cad }\end{array}$ & Vit $<\mathbf{2 0}$ & $\begin{array}{l}\text { Vit } \\
\mathbf{3 0}\end{array}$ & Vit $>\mathbf{3 0}$ & Total \\
\hline $\mathrm{N}$ & 58 & 17 & 6 & 81 \\
\hline $\mathrm{Y}$ & 10 & 5 & 4 & 19 \\
\hline Total & 68 & 22 & 10 & 100 \\
\hline
\end{tabular}

CAG findings in our study and their respective vitamin D level revealed 4 patients with normal coronaries and in them we found VDD in 0, VDI in 2 and normal in 2. In 31 patients having SVD VDD was in 20, VDI was in 7 , normal was in 4 . In patients having DVD we found VDD in 29, VDI in 11, normal in 3. In 22 patients having TVD we found VDD in 19, VDI in 2, normal vitamin D level in 1 . In our study we found statistically significant correlation 
showing Vitamin D level to be inversely related to the severity of CAD $(\mathrm{P}=0.0209)$ as presented in Table-8.

Table 8: Correlation of vitamin D and coronary angiography finding (no. of vessels involved).

\begin{tabular}{|lllll|}
\hline $\begin{array}{l}\text { Coronary angiography } \\
\text { (no of vessels involved) }\end{array}$ & $\begin{array}{l}\text { Vit } \\
<\mathbf{2 0}\end{array}$ & $\begin{array}{l}\text { Vit } \\
\mathbf{2 0}-\mathbf{3 0}\end{array}$ & $\begin{array}{l}\text { Vit } \\
\mathbf{>} \mathbf{3 0}\end{array}$ & Total \\
\hline 0 & 0 & 2 & 2 & 4 \\
\hline 1 & 20 & 7 & 4 & 31 \\
\hline 2 & 29 & 11 & 3 & 43 \\
\hline 3 & 19 & 2 & 1 & 22 \\
\hline Total & 68 & 22 & 10 & 100 \\
\hline
\end{tabular}

\section{DISCUSSION}

Large number of studies from all over the world have demonstrated low vitamin $\mathrm{D}$ level to be to be associated with high incidence of CAD and there is significant corelation between the two. So much so that serum vitamin $\mathrm{D}$ level can serve as an independent risk factor for CAD. Though conventional risk factors like DM, HTN, smoking, dyslipidemia are given importance in the workup of CAD, new risk factors like low vitamin $\mathrm{D}$ level is not given importance and corrective measures are not taken as a preventive step. Taking into account the paucity of studies of vitamin D level in CAD in this part of India this study was conducted to establish correlation between VDD and the conventional risk factors for CAD. This study also aimed to correlate vitamin D level with CAG findings.

In our study of 100 patients with 83 male and 17 female in a M:F ratio of 4.8:1 the mean age of patients was $59.38 \pm 10$ years. The mean vitamin D level was $17.60 \pm 8.05 \mathrm{ng} / \mathrm{ml}$ with normal vitamin D level in 10 patients, VDI in 22 and VDD in 68. The low level of vitamin D in CAD patients in our study was similar to studies by Syal SK and Goswamy $\mathrm{R}^{5,21}$

No association between age groups and vitamin D level $(p=0.289)$ was seen in our study, though theoretically as age advances the ability of the skin to synthesis vitamin D decreases. In contrast to our study Shojaeifard M observed significant decrease in Vitamin D level with advance in age. ${ }^{22}$

Verodia observed low Vitamin D in female making them prone for CAD in their study. In India with increase in indoor staying time, nutritional neglect specially in pregnant and lactating mothers have maximum risk for VDD and subsequent risk for CAD increases. However, our study did not show strong association between gender and Vitamin D level $(\mathrm{P}=378){ }^{23}$

There was no association between Vitamin D level and HTN in our study like that of Syal SK and van Bellegooijen study. ${ }^{21,24}$ But in contrast to our study Forman observed association of VDD with HTN. ${ }^{7}$
Pittas AG reviewing world literature observed a relatively constant association between low Vitamin D level and prevalence of Type-2 DM and MS. ${ }^{11}$ Ford ES observed that, odds of having MS decreased across increasing quintiles of concentration of $25-(\mathrm{OH}) \mathrm{D}$ and he also observed association between 25-(OH) D and MS does not differ between men and women. ${ }^{15}$ But our study did not show association of Vitamin D level with prevalence of DM. $(\mathrm{P}=0.105)$ Similar to Syal SK study which is an Indian study. ${ }^{21}$ This variation may be due to ethnic differences as observed by Sragg R. ${ }^{25}$

As cigarette smoking inhibits Vitamin D induced translocation of VDR from the nucleus to the cell membrane efficiency of Vitamin D decreases as observed by Uh ST et al. ${ }^{16}$ Though Brot C observed deleterious effect of smoking on Vitamin D level, our study did not show any significant correlation between Smoking and Vitamin D level. ${ }^{26}$

Significant link between family history (an important nonmodifiable risk factor) of CAD and Vitamin D level was observed by Entezari-Maleki, Taher. ${ }^{27}$ Schildkraut JM observed early age parental CAD death increases risk for $\mathrm{CAD}$ in women, whereas late age parental CAD death was associated with increased risk of CAD in men. However, our study had no relation of Vitamin D level with family history of CAD. ${ }^{28}$

Inverse relationship of Vitamin D level with dyslipidemia was found in our study $(\mathrm{P}=0.03)$ similar to Shojaeifard $\mathrm{M}$ Karhappa et al study. ${ }^{22,29}$ Contrasting was Wang H study where no therapeutic value of Vitamin D supplementation on lipid profile was found. ${ }^{30}$

In our study Vitamin D level was inversely co-related with significant $C A D$ angiographically $(P=0.02)$. VDD had significant association in SVD $(\mathrm{P}=0.046), \mathrm{DVD}(\mathrm{P}=0.017)$ and TVD $(\mathrm{P}=0.012)$ similar to Syal SK study. ${ }^{21}$ Our study also revealed patients with VDD to have high prevalence of DVD and TVD (53\% Vs 38\%), more diffuse CAD (56\% Vs 34\%) and higher number of coronary vessels involved when compared with patients with high 25 OHD levels. Patients with lower Vitamin D levels had significantly lower brachial artery flow mediated dilatation (FMD) [4.57\% Vs. $10.68 \%$ with $\mathrm{P}$ value of $<0.001$ ] comparing with high VDD level patients. Our study also revealed higher prevalence of VDD in CAD patients, similar to Shojaeifard $\mathrm{M}$ and Verodia studies. ${ }^{22,23}$ Higher rate of CAC was also observed in our study indicating higher plaque burden in patients with $\mathrm{CAD}$ having low Vitamin D levels.

\section{CONCLUSION}

Assessment of Vitamin D levels in patients with CAD has not been recognised as an essential part of clinical workup of patients or persons at risk for CAD. Large number of recent studies have demonstrated the inverse correlation of Vitamin D level with CAD and various cardiovascular risk 
factors. Hence this study was done to establish correlation of Vitamin D level with the conventional risk factors for $\mathrm{CAD}$ and CAG findings. In conclusion we observed no significant statistical correlation of Vitamin D level with conventional risk factors for CAD such as age, sex, hypertension, diabetes, smoking and family history of CAD except dyslipidemia. In our study we also observed VDD to be associated with sever CAD as evidenced by higher presence of multi vessel disease and presence of high CAC. In future studies involving large number of patients will throw more light on the role of VDD in CAD.

Funding: No funding sources

Conflict of interest: None declared

Ethical approval: The study was approved by the Institutional Ethics Committee

\section{REFERENCES}

1. World Health Organisation. World Health Statistics. Department of Measurement and Health Information Systems of the Information, Evidence and Research Cluster. Geneva: WHO Press; 2008:29-31.

2. Chapuy MC, Preziosi P, Maamer M, Arnaud S, Galan P, Hercberg S, et al. Prevalence of Vitamin D insufficiency in an adult normal population. Osteoporosis Int. 1997;7(5):439-43.

3. Ginde AA, Liu MC, Camargo CA. Demographic differences and trends of Vitamin D insufficiency in the US population, 1988-2004. Arch Med. 2009;169(6):626-32.

4. Harinarayan CV, Ramalakshmi T, Prasad UV, Sudhakar D. Vitamin D Status in Andhra Pradesh: A population based study. Indian $\mathrm{J}$ Med Res. 2008;127:211-8.

5. Goswami R, Gupta N, Goswami D, Marwaha RK, Tandon N, Kochupillai N. Prevalence and significance of low 25-hydroxy Vitamin D concentrations in healthy subjects in Delhi. Am J Clinic Nut. 2000;72(2):472-5.

6. Mithal A, Wahl DA, Bonjour JP, Burckhardt P, Dawson-Hughes B, Eisman JA, et al. Global Vitamin D Status and determinants of hypovitaminosis D. Osteo Int. 2009;20(11):1807-20.

7. Forman JP, Giovannucci E, Holmes MD, BischoffFerrari HA, Tworoger SS, Willett WC, et al. Plasma 25-hydroxy Vitamin D levels and risk of incident hypertension. Hypertension. 2007;49(5):1063-9.

8. Li YC. Molecular mechanism of Vitamin D in the Cardiovascular system. J Invest Med. 2011;59(6):86871.

9. Fitzpatrick LA, Bilezikian JP, Silverberg SJ. Parathyroid hormone and the Cardiovascular system. Current Osteoporosis Report. 2008;6(2):77-83.

10. Goel R.K, Lal H. Role of Vitamin D Supplementation in Hypertension. Indian $\mathbf{J}$ clinic Biochem. 2011;26(1):88-90.

11. Pittas AG, Lau J, Hu FB, Dawson-Hughes B. The role of Vitamin D and calcium in type 2 diabetes. A systematic review and meta-analysis. J clinic Endocrinol Metabol. 2007;92(6):2017-29.

12. Isaia G, Giorgino R, Adami S. High Prevalence of Hypovitaminosis $\mathrm{D}$ in Female Type 2 Diabetic population Seasonal Variation of glycemic control in type 2 diabetic patients. Diabetes Care. 2001;24:1503.

13. Chiu KC, Chu A, Go VL, Saad MF. Hypovitaminosis $\mathrm{D}$ is associated with insulin Resistance and beta cell dysfunction. Am J Clinic Nut. 2004;79(5):820-25.

14. Kelishadi R, Farajzadegan Z, Bahreynian M. Association between vitamin $\mathrm{D}$ status and lipid profile in children and adolescents: a systematic review and meta-analysis. Int J Food Sci Nut. 2014;65(4):404-10.

15. Ford ES, Ajani UA, McGuire LC, Liu S. Concentrations of serum Vitamin D and the Metabolic Syndrome Among U.S Adults. Diabet Care. 2005;28(5):1228-30.

16. Uh ST, Koo SM, Kim YK, Kim KU, Park SW, Jang AS, et al. Inhibition of Vitamin D receptor translocation by cigarette smoking Extracts. Tuberculosis Respiratory Disease. 2012;73(5):258-65.

17. Siadat ZD, Shariat AS, Sadeghi M, Kiani K, Farajzadegan Z, Kheirmand M. Vitamin D deficiency and coronary artery disease. J Res Med Sci. 2012;17:190-93.

18. Giovannucci E, Liu Y, Hollis BW, Rimm EB. 25hydroxyVitamin D and risk of Myocardial infarction in men: a prospective study. Archives Internal Medicine. 2008;168(11):1174-80.

19. Bair TL, Horne B, Anderson J, May H, Lappe D, Muhlestein J. Do levels of Vitamin D differ among patients with coronary artery disease based on Initial clinical presentation. J Am Col Cardiol. 2012;59(13):1386.

20. Young KA, Snell-Bergeon JK, Nail RG, Hokanson JE, Tarullo D, Gottlieb PA, et al. Vitamin D deficiency and coronary artery Calcification in subjects with type 1 diabetes. Diabet care. 2011;34(2):454-8.

21. Syal Sk, Kapoor A, Bhatia E, Sinha A, Kumar S, Tewari S, et al. Vitamin D deficiency and coronary artery disease, and endothelial dysfunction: observations from a coronary angiographic study in Indian patients. J Invasive Cardiol. 2012;24(8):385-9.

22. Shojaeifard M, Rahmanpour HR, Effatpanah M, Omidi N. Association between 25-hydroxy Vitamin D deficiency and severity of coronary artery involvement. Ann Bri Med Sci. 2015;1(1):10-3.

23. Verdoia M, Schaffer A, Barbieri L, Di Giovine G, Marino P, Suryapranata H, De Luca G, Novara Atherosclerosis Study Group. Impact of gender difference on vitamin D status and its relationship with the extent of coronary artery disease. Nutrition, Metabolism and Cardiovascular Diseases. 2015;25(5):464-70.

24. Van Ballegooijen AJ, Kestenbaum B, Sachs MC, De Boer IH, Siscovick DS, Hoofnagle AN, Ix JH, Visser M, Brouwer IA. Association of 25-hydroxyvitamin D and parathyroid hormone with incident hypertension: MESA (Multi-Ethnic Study of Atherosclerosis). 
Journal of the American College of Cardiology. 2014;63(12):1214-22.

25. Scragg R, Sowers M, Bell C. Serum 25HydroxyVitamin D, Diabetes, and Ethnicity in the Third National Health and Nutrition Examination Survey. Diabetes Care. 2004;27:2813-8.

26. Brot C, Jorgensen NR. Sorensen OH. The influence of smoking on Vitamin D status and calcium metabolism. Eur J Clinic Nutrition. 1999;53(12):920-6.

27. Entezari-Maleki T, Talasaz AH, Salarifar M, Hadjibabaie M, Javadi MR, Bozorgi A, et al. Plasma vitamin $\mathrm{D}$ status and its correlation with risk factors of thrombosis, P-selectin and hs-CRP level in patients with venous thromboembolism; the first study of iranian population. IJPR. 2014;13(1):319.

28. Schildkraut JM, Myers RH, Cupples LA, Kiely DK, Kannel WB. Coronary risk associated with age and sex of parental heart disease in the Framingham study. Am J Cardiol. 1989;64(10):555-9.
29. Karhapää P, Pihlajamäki J, Pörsti I, Kastarinen M, Mustonen J, Niemelä O, Kuusisto J. Diverse associations of 25-hydroxyvitamin $\mathrm{D}$ and 1, 25dihydroxy-vitamin D with dyslipidaemias. J Med. 2010;268(6):604-10.

30. Wang H, Xia N, Yang Y, Peng DQ. Influence of vitamin D supplementation on plasma lipid profiles: a meta-analysis of randomized controlled trials. Lipids in health and disease. 2012;11(1):42.

Cite this article as: Tripathy SK, Dhal N, Pattnaik S, Routray SN, Das S, Mishra SK, et al. The correlation of cardiovascular risk factors and angiographic findings with serum vitamin D levels in patients undergoing coronary angiography. Int $\mathbf{J}$ Basic Clin Pharmacol 2018;7:32-7. 